\title{
Clarifying the Diagnosis of Clinically Suspected Recurrence of Cervical Cancer: Impact of ${ }^{18}$ F-FDG PET
}

\author{
Astrid A.M. van der Veldt ${ }^{1}$, Marrije R. Buist ${ }^{2}$, Marchien W. van Baal ${ }^{3}$, Emile F. Comans ${ }^{1}$, Otto S. Hoekstra ${ }^{1}$, and
} Carla F.M. Molthoff ${ }^{1}$

${ }^{I}$ Department of Nuclear Medicine and PET Research, VU University Medical Center, Amsterdam, The Netherlands; ${ }^{2}$ Department of Obstetrics and Gynecology, Academic Medical Center, Amsterdam, The Netherlands; and ${ }^{3}$ Department of Obstetrics and Gynecology, VU University Medical Center, Amsterdam, The Netherlands

Clarifying the diagnosis of clinically suspected recurrence of cervical cancer can be challenging. The aim of this study was to investigate the clinical value of ${ }^{18} \mathrm{~F}-\mathrm{FDG}$ PET in this context. Methods: The medical records of a cohort of $40{ }^{18} \mathrm{~F}-\mathrm{FDG}$ PET referrals in whom recurrence of cervical cancer was clinically suspected were reviewed. Two expert gynecologic oncologists assessed the level of pre-PET clinical doubt, quality of pre-PET work-up, and impact of ${ }^{18}$ F-FDG PET on diagnostic understanding and management using questionnaires. Results: In patients with clinically equivocal recurrence, ${ }^{18} \mathrm{~F}$-FDG PET had a sensitivity of $92 \%$ and a specificity of $93 \%$ (prevalence, $65 \%$ ). Before ${ }^{18} \mathrm{~F}$ FDG PET, there was high disagreement about the adequacy of the conventional work-up (intraclass correlation coefficient [ICC], 0.25) and the presence of recurrence (ICC, 0.24). ${ }^{18} \mathrm{~F}-$ FDG PET increased experts' confidence (median increase, $14 \%$ and $25 \% ; P<0.0001$ ) and diagnostic agreement (from $68 \%$ to $98 \%$; ICC, from 0.24 to 0.95 ). When ${ }^{18} \mathrm{~F}-\mathrm{FDG}$ PET was positive for recurrence, the median overall survival was $13 \mathrm{mo}$. For patients with negative ${ }^{18} \mathrm{~F}-\mathrm{FDG}$ PET findings, the median survival was not reached (log rank, 15.50, $P=0.0001$ ). When the treatment plan was categorized as local therapy, systemic therapy, and expectative management, ${ }^{18}$ F-FDG PET changed the treatment plan in half of all cases. The 2 experts reported that ${ }^{18}$ F-FDG PET led to a better diagnosis and a beneficial change in management in, respectively, $60 \%$ and $65 \%$ of cases. Conclusion: ${ }^{18} \mathrm{~F}-\mathrm{FDG}$ PET can help to clarify the diagnosis of clinically suspected recurrence of cervical cancer. In this patient population, ${ }^{18} \mathrm{~F}$-FDG PET had significant value in diagnostic understanding and management of recurrent cervical cancer, facilitating decision making and treatment planning. Therefore, ${ }^{18} \mathrm{~F}-\mathrm{FDG}$ PET should be part of the diagnostic work-up in detection of recurrent cervical cancer. The high positive predictive value of ${ }^{18} \mathrm{~F}-\mathrm{FDG} P E T$ in these patients suggests that inclusion in intervention trials might be based on a positive ${ }^{18}$ F-FDG PET scan.

Received Jun. 9, 2008; revision accepted Sep. 2, 2008

For correspondence or reprints contact: Astrid A.M. van der Veldt, VU University Medical Center, Department of Nuclear Medicine and PET Research, P.O. Box 7057, 1007 MB Amsterdam, The Netherlands.

E-mail: aam.vanderveldt@vumc.nl

COPYRIGHT @ 2008 by the Society of Nuclear Medicine, Inc.
Key Words: ${ }^{18}$ F-FDG PET; cervical cancer; recurrence; management J Nucl Med 2008; 49:1936-1943

DOI: 10.2967/jnumed.108.055046

C ervical cancer is the second most frequently diagnosed cancer in women worldwide (1). Depending on the stage of the disease, primary treatment consists of surgery, radiotherapy, chemotherapy, or a combination of these. After treatment for stage IB or higher, approximately one third of patients will have a recurrence $(2,3)$. For recurrent disease, curative and palliative therapies prevail (4-6); some patients with localized recurrence may be cured with appropriate aggressive therapy $(4,5)$. However, curative therapy is futile in the presence of distant metastases but may induce unnecessary morbidity.

Clinical suspicion of recurrent disease most often arises from symptoms (pain, lymph edema), rising tumor markers (SCC or CA-125), or radiologic findings. Imaging with CT or MRI has limitations in distinguishing recurrences and iatrogenic changes $(7,8)$. Taking representative biopsies of radiologically equivocal lesions proves to be difficult, so that diagnosis of recurrent disease can be a major clinical challenge. This obviously leads to prolonged anxiety in patients and delay of treatment. ${ }^{18} \mathrm{~F}-\mathrm{FDG}$ PET seems to have an acceptable diagnostic performance in suspected recurrent cervical cancer (9-12), and it may affect patient management (13). Furthermore, ${ }^{18}$ F-FDG avidity may predict the prognosis of recurrent cervical cancer (13). Taken together, prognostic stratification on noninvasive tests would imply a major improvement. The aim of the present retrospective analysis was to explore the potential role of ${ }^{18} \mathrm{~F}$-FDG PET in the context of clinically equivocal recurrent cervical cancer.

\section{MATERIALS AND METHODS}

\section{Patients}

In a retrospective analysis, we identified all consecutive patients referred for ${ }^{18}$ F-FDG PET because of equivocal clinical symptoms 
or findings or radiologic test results on the presence of recurrent cervical cancer. Patients with histologically confirmed cervical cancer and primary treatment with curative intent were eligible. The conventional work-up (CWU) was recorded and comprised physical examination, laboratory findings, and radiologic imaging. ${ }^{18}$ F-FDG PET was performed at the Department of Nuclear Medicine and PET Research, VU University Medical Center, Amsterdam, The Netherlands. After ${ }^{18}$ F-FDG PET, clinical followup was at least $12 \mathrm{mo}$. We reviewed all available medical records to document the clinical follow-up.

\section{${ }^{18}$ F-FDG PET and Analysis}

After patients had fasted for at least $6 \mathrm{~h}$, whole-body ${ }^{18} \mathrm{~F}-\mathrm{FDG}$ PET scans (vertex to mid thighs) were performed using an ECAT HR + PET scanner (Siemens/CTI). Two-dimensional emission scans of 5 min per bed position were performed, starting about 60 min after intravenous administration of ${ }^{18}$ F-FDG (370 MBq). Serum glucose levels were within the reference range in all patients. Patients were orally hydrated in advance and instructed to void before scanning started, to reduce physiologic urinary tract activity. All scans were corrected for decay, scatter, and randoms. Scan data were reconstructed by ordered-subset expectation maximization with 2 iterations and 16 subsets, followed by smoothing of the reconstructed image using a Hanning filter at Nyquist frequency. Attenuation correction was not performed (14).

An independent, experienced ( $>10$ y reading PET results) nuclear medicine physician, who was unaware of the patients' histories and outcomes, analyzed the ${ }^{18}$ F-FDG PET images. Focally enhanced ${ }^{18} \mathrm{~F}$-FDG uptake other than physiologic uptake was interpreted as potentially malignant. Previously obtained CT and MRI scans were available for localization of PET abnormalities. ${ }^{18} \mathrm{~F}$-FDG PET and CWU results were compared with the true lesion status obtained by histopathology or clinical follow-up and were classified as true-positive, true-negative, false-positive, or falsenegative. In the setting of the accuracy determination, we classified a negative clinical follow-up at 12 mo after ${ }^{18} \mathrm{~F}$-FDG PET as absence of recurrence.

\section{Data Analysis}

Two independent gynecologic oncologists (14 and $19 \mathrm{y}$ of experience in gynecology), from 2 different academic centers, were asked for an objective expert opinion. The 2 experts were unaware of the patients' outcome and completed questionnaires consisting of 3 parts (Appendix). In the first part, questions were based on the medical and radiologic reports before ${ }^{18} \mathrm{~F}$-FDG PET. Physicians were asked to provide their opinion on the adequacy of the CWU, the diagnosis and extent of recurrence, their confidence about the diagnosis (using a visual analog scale), and the management plan. The second part presented the ${ }^{18}$ F-FDG PET results of the masked nuclear medicine physicians and the same questions were repeated. In the third part, the actual treatment and follow-up of the individual patients were provided, and the 2 experts were requested to rate the usefulness of ${ }^{18} \mathrm{~F}$-FDG PET retrospectively. For this purpose, the impact on diagnostic understanding and treatment plan was graded by a method adapted from Wittenberg et al. (15-17). This method involves the following 5-point ordinal scale, with higher scores representing an increase in positive impact: ${ }^{18} \mathrm{~F}$-FDG PET led me to choose therapy that, in retrospect, was not in the best interest of the patient (1), ${ }^{18}$ F-FDG PET led to investigations I would not otherwise have performed, but this did not harm the patient (2), ${ }^{18} \mathrm{~F}-\mathrm{FDG}$ PET was of no influence in my diagnosis and choice of treatment (3), ${ }^{18} \mathrm{~F}$-FDG PET provided information that substantially improved my understanding of this patient's disease but did not alter my choice of treatment (4), and ${ }^{18}$ F-FDG PET led to a better diagnosis and led to a beneficial change in management (5).

\section{Statistical Analysis}

Statistical analysis was performed using SPSS software (version 15.0 for Windows; SPSS, Inc.). The level of interobserver agreement on the presence or absence of recurrent disease was assessed with intraclass correlation coefficients (ICCs) (18). In this setting, ICC is the proportion of total variance that can be ascribed to "true" differences. Values for the ICC range from 0 to 1 . Values close to 0 indicate poor agreement, whereas values close to 1 indicate high agreement. ICC values obtained from the fixed-effects ANOVA tables are comparable to weighted $\mathrm{\kappa}$-scores, with the weighted $\kappa$ calculated using quadratic weights. The Wilcoxon signed rank test was performed to compare the expert's confidence about the diagnosis before and after ${ }^{18} \mathrm{~F}$-FDG PET. To explore the prognostic value of CWU and ${ }^{18}$ F-FDG PET, the Kaplan-Meier method was used. Survival was the time between the date of ${ }^{18} \mathrm{~F}-\mathrm{FDG}$ PET and the date of death or the date at which patients were last known to be alive.

\section{RESULTS}

\section{Patient Population}

A total of 40 eligible patients were identified (median age at initial presentation, $41 \mathrm{y}$; range, 27-61 y). One patient was excluded because of insufficient clinical data. Patients had presented with cervical cancer of at least Fédération Internationale de Gynécologie et d'Obstétrique stage IB (Table 1). Primary treatment had consisted of surgery $(n=11)$, radiotherapy $(n=7)$, chemoradiation $(n=13)$, surgery and radiotherapy $(n=3)$, surgery and chemotherapy $(n=1)$, or surgery and chemoradiation $(n=5)$.

In most patients $(58 \%)$, clinical symptoms (e.g., pain) were the first symptoms bringing on a suspicion of recurrence, but equivocal lesions on $\mathrm{CT}$ or MRI were the most frequently reported indications for ${ }^{18} \mathrm{~F}-\mathrm{FDG}$ PET $(60 \%)$ (Table 2). The median time to ${ }^{18} \mathrm{~F}$-FDG PET was 16 mo (interquartile range [IQR], 10-34 mo) from primary presentation of cervical cancer (Table 1) and 3 mo (IQR, 1-5 mo) from first suspicion of recurrence. The median follow-up after ${ }^{18} \mathrm{~F}$-FDG PET was $18 \mathrm{mo}$ (IQR, 10-37 mo) for the total patient population and $36 \mathrm{mo}$ (IQR, 19-50 mo) for patients with a negative ${ }^{18}$ F-FDG PET result.

In these patients with clinically equivocal recurrences, ${ }^{18}$ F-FDG PET had a sensitivity of $92 \%$ (95\% confidence interval [CI], 81\%-96\%), a specificity of $93 \%(95 \% \mathrm{CI}$, $71 \%-100 \%)$, a positive predictive value of $96 \%(95 \% \mathrm{CI}$, $84 \%-100 \%)$, and a negative predictive value of $87 \%(95 \%$ CI, 66\%-93\%). Two patients had a false-negative ${ }^{18} \mathrm{~F}-\mathrm{FDG}$ PET result. One had lung, mediastinal, and paraaortic lymph node metastases, and the other had a pelvic recurrence, clinically detected 6 and 10 mo, respectively, after a ${ }^{18} \mathrm{~F}-\mathrm{FDG}$ PET examination with negative results. There was 1 falsepositive result, showing a retrovesical ${ }^{18} \mathrm{~F}-\mathrm{FDG}$ focus, also suggestive at CT. 
TABLE 1

Patient Characteristics

\begin{tabular}{lc}
\hline \multicolumn{1}{c}{ Characteristic } & Value \\
\hline No. of patients & 40 \\
Median age at diagnosis (y) & (range, 27-61) \\
FIGO stage ( $n$ ) & 13 \\
IB & 3 \\
IIA & 6 \\
IIB & 1 \\
IIIA & 13 \\
IIIB & 1 \\
IVA & 1 \\
IVB & 2 \\
Unknown & 25 \\
Histology ( $n$ ) & 11 \\
Squamous cell carcinoma & 2 \\
Adenocarcinoma & 1 \\
Large cell & 1 \\
Glassy cell & \\
Unknown & 11 \\
Primary therapy (n) & 7 \\
Surgery & 13 \\
Radiotherapy & 3 \\
Chemoradiation & 1 \\
Surgery + radiotherapy & $5 R, 10-37)$ \\
Surgery + chemotherapy & \\
Surgery + chemoradiation & \\
Median time to ${ }^{18}$ F-FDG PET & \\
after primary presentation (mo) & \\
Median duration of follow-up after & \\
18F-FDG PET (mo) & \\
& \\
\hline FIGO = Fédération Internationale de Gynécologie et d'Obstétrique. & \\
\hline & \\
\hline
\end{tabular}

For staging of recurrent disease, ${ }^{18} \mathrm{~F}-\mathrm{FDG}$ PET accurately detected local recurrence in 9 cases (sensitivity, 100\%; specificity, 97\%), regional recurrence in 13 cases (sensitivity, 87\%; specificity, 100\%), and distant metastases in 6 cases (sensitivity, 75\%; specificity, 100\%). The lower sensitivity for distant metastases was caused by 2 false-negative results in 2 patients with lung metastases found 5 and 6 mo, respectively, after ${ }^{18} \mathrm{~F}-\mathrm{FDG}$ PET. The ${ }^{18} \mathrm{~F}-\mathrm{FDG}$ PET readings of the masked nuclear medicine physician were highly congruent with the original ${ }^{18} \mathrm{~F}$-FDG PET reports (95\% for the presence of recurrence, $93 \%$ for the extent of recurrence; Table 3 ).

TABLE 2

Indications for ${ }^{18} \mathrm{~F}$-FDG PET

\begin{tabular}{lcc}
\hline Sign or symptom & $\begin{array}{c}\text { Cause of } \\
\text { first clinical } \\
\text { suspicion }\end{array}$ & $\begin{array}{c}\text { Indication for } \\
\text { 18F-FDG PET }\end{array}$ \\
\hline Elevated tumor markers & 7 & 3 \\
Equivocal lesions on CT or MRI & 8 & 24 \\
Clinical symptoms & 23 & 3 \\
Abnormality on physical & 2 & - \\
$\quad$ examination & & 10 \\
Equivocal result on & - & \\
pathologic examination & & \\
\hline
\end{tabular}

TABLE 3

Reading by Experienced Nuclear Medicine Physician and Original ${ }^{18} \mathrm{~F}-\mathrm{FDG}$ PET Report

\begin{tabular}{|c|c|c|c|c|c|}
\hline \multirow{3}{*}{$\begin{array}{c}\text { Expert }{ }^{18} \mathrm{FDG} \text { PET } \\
\text { reading }\end{array}$} & \multicolumn{5}{|c|}{ Original ${ }^{18} \mathrm{FDG}$ PET report } \\
\hline & \multirow[b]{2}{*}{ Present } & \multicolumn{3}{|c|}{ Recurrence* $^{\star}$} & \multirow[b]{2}{*}{ Absent } \\
\hline & & Local & Regional & Distant & \\
\hline Present & 24 & 0 & 0 & 0 & 1 \\
\hline \multicolumn{6}{|l|}{ Recurrence* } \\
\hline Local & 0 & 8 & 0 & 0 & 1 \\
\hline Regional & 0 & 0 & 13 & 0 & 0 \\
\hline Distant & 0 & 0 & 0 & 6 & 0 \\
\hline Absent & 1 & 1 & 0 & 0 & 14 \\
\hline
\end{tabular}

*Recurrence of disease was categorized as local, regional, and distant. For example, when local recurrence with distant metastases was suspected, patient's extent of recurrence was categorized as "local" and "distant."

In retrospect, 26 patients $(65 \%)$ had recurrent disease at the time of ${ }^{18}$ F-FDG PET. Six of them were treated with curative intent. In 2 patients ( 1 with exenterative surgery and chemotherapy and 1 with chemoradiation), continued follow-up for more than 35 mo showed no evidence of disease. Three patients died within $36 \mathrm{mo}$, and 1 patient had an incurable rerecurrence within 30 mo after exenterative surgery. In addition, 2 patients were diagnosed with recurrent disease at 35 and 46 mo after a ${ }^{18}$ F-FDG PET examination with negative results. At the end of follow-up, 23 patients had died of their disease, 3 were alive with disease, and 14 had no evidence of disease.

\section{Clinical Expert Opinion}

In 29 cases (73\%), at least 1 expert reported inadequate CWU; in 14 cases (35\%), both experts reported inadequacy. Considerable disagreement existed between the 2 observers about the adequacy of the CWU (ICC, 0.25). Additional imaging (e.g., bone scintigraphy, CT, and MRI) and biopsies were most frequently reported to be missing. On the basis of the clinical data before ${ }^{18} \mathrm{~F}-\mathrm{FDG}$ PET, the 2 experts had a median confidence of $65 \%$ and $50 \%$ about their diagnoses (Table 4), with poor agreement between them (ICC, 0.24). After ${ }^{18} \mathrm{~F}-\mathrm{FDG}$ PET, the experts changed their diagnoses on the presence of recurrence in $25 \%$ and $30 \%$ of cases and concerning the extent of recurrence in $38 \%$ and $53 \%$ of cases. In 5 and 3 cases, the 2 experts correctly changed the status of recurrent disease from absence to presence of distant metastases. ${ }^{18} \mathrm{~F}-\mathrm{FDG}$ PET results increased the diagnostic confidence of the experts by a median of $14 \%$ and $25 \%$ (Wilcoxon signed rank test, $P<0.0001)$. Furthermore, ${ }^{18} \mathrm{~F}$-FDG PET improved the diagnostic agreement on the presence of recurrence by $30 \%$ (from $68 \%$ to $98 \%$; ICC, from 0.24 to 0.95 ).

${ }^{18} \mathrm{~F}-\mathrm{FDG}$ PET was strongly predictive of overall survival (log rank, 15.50; $P=0.0001$ ), and this was significantly better than the predictive value of the CWU results of the individual experts (Fig. 1). When ${ }^{18}$ F-FDG PET was positive 
TABLE 4

Diagnosis Before and After ${ }^{18} \mathrm{~F}$-FDG PET

\begin{tabular}{|c|c|c|c|c|}
\hline Diagnosis & Before PET & After PET & Changed & $\begin{array}{l}\text { Change in } \\
\text { diagnosis } \\
\text { specified }^{*}\end{array}$ \\
\hline \multicolumn{5}{|l|}{ Expert 1} \\
\hline Recurrence, $n(\%)$ & $28(70)$ & $24(60)$ & $12(30)$ & $(-8,+4)$ \\
\hline \multicolumn{5}{|l|}{ Extent of recurrence, $n(\%)^{\dagger}$} \\
\hline Local & $17(43)$ & $8(20)$ & $14(35)$ & $(-12,+2)$ \\
\hline Regional & $11(28)$ & $13(33)$ & $10(25)$ & $(-4,+6)$ \\
\hline Distant & $3(8)$ & $6(15)$ & $7(18)$ & $(-2,+5)$ \\
\hline Median confidence about diagnosis, \% (IQR) $)^{\ddagger}$ & $65(58-73)$ & $82(71-89)$ & $+14(6-23)$ & \\
\hline \multicolumn{5}{|l|}{ Expert 2} \\
\hline Recurrence, $n(\%)$ & $27(68)$ & $23(58)$ & $10(25)$ & $(-7,+3)$ \\
\hline \multicolumn{5}{|l|}{ Extent of recurrence, $n(\%)^{\dagger}$} \\
\hline Local & $9(23)$ & $9(23)$ & $10(25)$ & $(-5,+5)$ \\
\hline Regional & $16(40)$ & $12(30)$ & $12(30)$ & $(-8,+4)$ \\
\hline Distant & $6(15)$ & $7(18)$ & $5(13)$ & $(-2,+3)$ \\
\hline Median confidence about diagnosis, \% (IQR) ${ }^{\ddagger}$ & $50(50-63)$ & $80(70-90)$ & $+25(10-30)$ & \\
\hline \multicolumn{5}{|c|}{$\begin{array}{l}{ }^{\star} \text { Number of cases in which presence or extent of recurrence was decreased }(-) \text { or increased }(+) \text { with added }{ }^{18} \mathrm{~F}-\mathrm{FDG} \text { PET information. } \\
{ }^{\dagger} \text { Extent of disease was categorized as local, regional, and distant recurrence. For example, when local recurrence with distant } \\
\text { metastases was suspected, patient's extent of recurrence was categorized as "local" and "distant"; percentage of cases was defined as } \\
\text { percentage of total number of cases }(n=40) \text {. } \\
\left.{ }^{\ddagger} \text { Confidence of expert about diagnosis significantly increased after }{ }^{18} \mathrm{~F}-\mathrm{FDG} \text { PET (Wilcoxon signed rank test, } P<0.0001\right) \text {. }\end{array}$} \\
\hline
\end{tabular}

for recurrence, the median overall survival was 13 mo. For patients with ${ }^{18} \mathrm{~F}$-FDG PET findings negative for recurrence, the median survival was not reached.

When the treatment plan was categorized as local therapy (surgery, radiotherapy, hyperthermia), systemic therapy (chemotherapy or palliative treatment consisting of supportive care), and expectative management, ${ }^{18} \mathrm{~F}$-FDG PET changed the treatment plans of the 2 experts in $19(48 \%)$ and $20(50 \%)$ cases (Table 5). Local therapy was the most frequently changed treatment modality ( 7 and 10 cases), followed by systemic therapy (both experts, 6 cases). Radiotherapy was the most frequently changed local therapy (both experts, 4 cases), whereas chemotherapy was the most frequently changed systemic treatment (both experts, 3 cases). In 3 and 5 cases, ${ }^{18}$ F-FDG PET revealed unexpected distant metastases, preventing extensive locoregional therapy in 1 and 2 cases, respectively. In 6 cases (15\%), both experts changed the intent of the management plan (curative vs. palliative intent), mainly because of a change in the extent of the disease. In $80 \%$ of the cases, the expert management plan was similar to what happened in clinical practice (Table 6). Finally, the experts reported that ${ }^{18} \mathrm{~F}-\mathrm{FDG}$ PET led to a better diagnosis and a beneficial change in management in $60 \%$ and $65 \%$ of cases, respectively (Table 7).

\section{DISCUSSION}

The current study is the first, to our knowledge, to report on the added value of ${ }^{18} \mathrm{~F}$-FDG PET on a measured and externally validated level of uncertainty about the presence of recurrent cervical cancer. Before ${ }^{18} \mathrm{~F}$-FDG PET, the expert panel reported inadequacy of the CWU and high disagree- ment about the diagnosis with low ICC values. We found considerable added value for ${ }^{18}$ F-FDG PET not only in terms of expert opinion but also in terms of substantiated accuracy

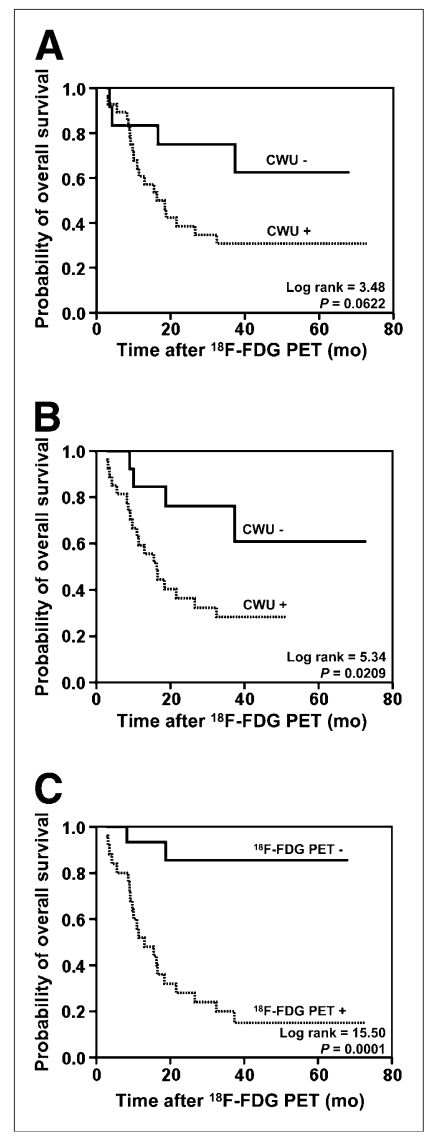

FIGURE 1. Kaplan-Meier curves for overall survival of patients with clinically suspected recurrence of cervical cancer according to CWU of experts 1 (A) and 2 (B) and according to ${ }^{18} \mathrm{~F}-$ FDG PET (C). 
TABLE 5

Change in Management

\begin{tabular}{|c|c|c|c|c|}
\hline Management & Before PET $(n)$ & After PET $(n)$ & Changed $^{\star}(n)$ & Change in diagnosis specified ${ }^{\dagger}$ \\
\hline \multicolumn{5}{|l|}{ Expert 1} \\
\hline Local therapy ${ }^{\ddagger}$ & 17 & 14 & 10 & \\
\hline Surgery (1) & 6 & 5 & 2 & $1 \rightarrow 6(2 \times)$ \\
\hline Radiotherapy (2) & 7 & 6 & 4 & $2 \rightarrow 6(4 \times)$ \\
\hline Hyperthermia (3) & 5 & 3 & 4 & $3 \rightarrow 2,3 \rightarrow 5,3 \rightarrow 6(2 \times)$ \\
\hline Systemic therapy & 11 & 9 & 6 & \\
\hline Chemotherapy (4) & 6 & 3 & 3 & $4 \rightarrow 2,4 \rightarrow 5,4 \rightarrow 6$ \\
\hline Palliative treatment (5) & 5 & 6 & 3 & $5 \rightarrow 1,5 \rightarrow 3,5 \rightarrow 4$ \\
\hline Expectative (6) & 12 & 17 & 4 & $6 \rightarrow 1,6 \rightarrow 2,6 \rightarrow 5(2 \times)$ \\
\hline Curative $^{\S}$ & 26 & 26 & 4 & Curative $\rightarrow$ palliative $(4 \times)$ \\
\hline Palliative & 14 & 14 & 2 & Palliative $\rightarrow$ curative $(2 \times)$ \\
\hline \multicolumn{5}{|l|}{ Expert 2} \\
\hline Local therapy $\ddagger$ & 13 & 13 & 7 & \\
\hline Surgery (1) & 0 & 2 & 0 & - \\
\hline Radiotherapy (2) & 7 & 8 & 4 & $2 \rightarrow 4,2 \rightarrow 6(3 x)$ \\
\hline Hyperthermia (3) & 5 & 3 & 3 & $3 \rightarrow 4,3 \rightarrow 6(2 x)$ \\
\hline Systemic therapy & 6 & 6 & 6 & \\
\hline Chemotherapy (4) & 6 & 6 & 3 & $4 \rightarrow 2(3 \times)$ \\
\hline Palliative treatment (5) & 0 & 0 & 0 & - \\
\hline Expectative (6) & 22 & 21 & 6 & $6 \rightarrow 1(2 \times), 6 \rightarrow 2(2 \times), 6 \rightarrow 3,6 \rightarrow 4$ \\
\hline Curative $§$ & 22 & 24 & 2 & Curative $\rightarrow$ palliative $(2 \times)$ \\
\hline Palliative & 18 & 16 & 6 & Palliative $\rightarrow$ curative $(4 \times)$ \\
\hline \multicolumn{5}{|c|}{$\begin{array}{l}{ }^{*} \text { Number of cases in which pre-PET management plan was changed after }{ }^{18} \text { F-FDG PET. } \\
{ }^{\dagger} \text { Change in management specified: } 1 \text {, surgery; } 2 \text {, radiotherapy; } 3 \text {, hyperthermia; } 4 \text {, chemotherapy; } 5 \text {, palliative treatment; and } 6 \text {, } \\
\text { expectative. } \\
{ }^{\ddagger} \text { Local therapy for localized recurrence that could be combined with other treatment modalities. Surgery could be combined with } \\
\text { radiotherapy, chemoradiation, hyperthermia, or chemotherapy. Radiotherapy could be combined with hyperthermia or chemotherapy. } \\
\text { Hyperthermia could be combined with chemotherapy. } \\
{ }^{\S} \text { Management plans of patients without suspicion of recurrence were classified under curative intent. }\end{array}$} \\
\hline
\end{tabular}

measures for detection (sensitivity or specificity $>90 \%$ ) and staging. Furthermore, ${ }^{18}$ F-FDG PET affected treatment planning, and ${ }^{18}$ F-FDG PET results had a higher prognostic value than did CWU. A high agreement between physicians facilitates decision making on treatment planning. The low rate of false-positive results and high prognostic value suggest that ${ }^{18} \mathrm{~F}$-FDG PET is an important diagnostic tool for detecting recurrent cervical cancer in clinically equivocal patients.

For treatment planning, we have extended the study by Chung et al. (13), which reported that ${ }^{18} \mathrm{~F}-\mathrm{FDG}$ PET/CT

TABLE 6

Actual Management, Compared with Management of Expert

\begin{tabular}{|c|c|c|c|c|}
\hline \multirow{2}{*}{$\begin{array}{l}\text { Retrospective management } \\
\text { after }{ }^{18} \mathrm{~F}-\mathrm{FDG} \text { PET }\end{array}$} & \multicolumn{4}{|c|}{ Actual management } \\
\hline & Surgery* & Radiotherapy ${ }^{\dagger}$ & Systemic therapy ${ }^{\ddagger}$ & Expectative \\
\hline \multicolumn{5}{|l|}{ Expert 1} \\
\hline Surgery* & 2 & 3 & 0 & 0 \\
\hline Radiotherapy ${ }^{\dagger}$ & 1 & 6 & 2 & 0 \\
\hline Systemic therapy ${ }^{\ddagger}$ & 0 & 1 & 7 & 1 \\
\hline Expectative & 0 & 0 & 0 & 17 \\
\hline \multicolumn{5}{|l|}{ Expert 2} \\
\hline Surgery* & 2 & 0 & 0 & 0 \\
\hline Radiotherapy ${ }^{\dagger}$ & 0 & 9 & 2 & 0 \\
\hline Systemic therapy ${ }^{\ddagger}$ & 0 & 2 & 4 & 0 \\
\hline Expectative & 0 & 1 & 3 & 17 \\
\hline $\begin{array}{l}{ }^{\star} \text { Surgery could be combined } \\
{ }^{\dagger} \text { Radiotherapy or hypertherm } \\
{ }^{\ddagger} \text { Chemotherapy alone or pall }\end{array}$ & $\begin{array}{l}\text { erapy, cr } \\
\text { combine } \\
\text { ent cons }\end{array}$ & $\begin{array}{l}\text { on, hyperthermi } \\
\text { rthermia or che } \\
\text { oportive care. }\end{array}$ & therapy. & \\
\hline
\end{tabular}


TABLE 7

Impact of ${ }^{18} \mathrm{~F}-\mathrm{FDG}$ PET on Diagnostic Understanding and Management ${ }^{\star}$

\begin{tabular}{|c|c|c|}
\hline Impact & Expert $1(\%)$ & Expert $2(\%)$ \\
\hline $\begin{array}{l}{ }^{18} \mathrm{~F}-\mathrm{FDG} \text { PET led me to choose therapy that, in retrospect, was not in best } \\
\text { interest of patient. }\end{array}$ & 2.5 & 2.5 \\
\hline $\begin{array}{l}{ }^{18} \text { F-FDG PET led to investigations I would not otherwise have performed, } \\
\text { but this did not harm patient. }\end{array}$ & 2.5 & 0.0 \\
\hline${ }^{18} \mathrm{~F}-\mathrm{FDG}$ PET was of no influence in my diagnosis and choice of treatment. & 7.5 & 15.0 \\
\hline $\begin{array}{l}{ }^{18} \mathrm{~F}-\mathrm{FDG} \text { PET provided information that substantially improved my understanding } \\
\text { of this patient's disease but did not alter my choice of treatment. }\end{array}$ & 27.5 & 17.5 \\
\hline${ }^{18} \mathrm{~F}-\mathrm{FDG}$ PET led to better diagnosis and to beneficial change in management. & 60.0 & 65.0 \\
\hline
\end{tabular}

${ }^{*}$ Adapted from Wittenberg et al. (15-17).

changed management in $23.1 \%$ of cases in suspected recurrent cervical cancer. However, in the current study the experts reported a potential change in management in almost half of all cases (48\% and 50\%). In 5 and 9 of these cases, respectively, ${ }^{18} \mathrm{~F}-\mathrm{FDG}$ PET might have saved patients from the morbidity of active treatment regimens; treatment plans consisting of surgery, radiotherapy, hyperthermia, or chemotherapy might have been changed to expectative management as a result of an improved assessment of dissemination.

The potential impact of ${ }^{18} \mathrm{~F}$-FDG PET on the treatment plan might be even higher, because the current analysis did not discriminate between local therapy and its adjuvant treatment (e.g., surgery with or without subsequent chemotherapy; Table 5). The higher frequency of change in treatment plan management found in our study, compared with the findings in the study of Chung et al. (13), may be explained by differences in the actual level of uncertainty. However, the retrospective design of the current study might pose a possible limitation because unknown factors not described in the medical records may have contributed to the original decision-making process. Nevertheless, in $80 \%$ of the cases, the expert management plan was similar to what happened in clinical practice. The observed discrepancies were random and few.

Some other studies have documented that ${ }^{18}$ F-FDG PET can change the management of recurrent cervical cancer $(10,19) .{ }^{18} \mathrm{~F}-\mathrm{FDG}$ PET seemed important in determining whether patients can be treated with curative intent $(20,21)$.

Six of 26 patients who were diagnosed after signs and symptoms became apparent received curative treatment. However, only 2 of them remained disease-free for more than $35 \mathrm{mo}$, as is typically observed in symptomatic patients (22). It is yet unclear whether earlier diagnosis of recurrence will improve patient outcome, that is, whether our patients would have benefited from an earlier ${ }^{18} \mathrm{~F}$-FDG PET scan.

If ${ }^{18} \mathrm{~F}$-FDG PET were to be applied as a screening procedure in asymptomatic patients, the presently observed predictive values cannot be directly extrapolated. The much lower prevalence in such patients will result in higher false- positivity rates (23). Projecting our sensitivity and specificity on a prevalence of $12 \%$ (23), the false-positive rate would be about $40 \%$, at a negative predictive value of $99 \%$.

Recurrent cervical cancer continues to be a therapeutic dilemma, and prospective randomized clinical trials are necessary to evaluate new treatment strategies to prolong survival. Intervention trials require objective diagnostic procedures to detect and evaluate recurrent disease. However, detecting clinically suspected cervical cancer can be challenging, as illustrated by the reported inadequacy of the CWU, the rather low confidence of the experts, and the low diagnostic agreement among them. In the majority of cases, a suspicion of recurrence was first raised by clinical symptoms and elevated tumor markers, but these were not the direct indications for ${ }^{18} \mathrm{~F}-\mathrm{FDG}$ PET (Table 2). Equivocal results of CT, MRI, and pathologic examination almost completely covered the spectrum of indications to apply for an ${ }^{18} \mathrm{~F}-\mathrm{FDG}$ PET examination, indicating that these diagnostic tests do not provide conclusive evidence in confirmation of recurrence. When a recurrence of cervical cancer was clinically suspected, ${ }^{18}$ F-FDG PET had high accuracy in detecting and staging recurrence and was of major additional value in diagnostic understanding and treatment planning. Furthermore, the use of ${ }^{18} \mathrm{~F}-\mathrm{FDG}$ PET/CT (rather than ${ }^{18} \mathrm{~F}-\mathrm{FDG}$ PET) in these patients will likely reduce the number of diagnostic tests and help to identify biopsy sites, avoiding interpretation problems due to poor anatomic localization at ${ }^{18}$ F-FDG PET alone $(13,24)$.

In current practice, ${ }^{18} \mathrm{~F}-\mathrm{FDG}$ PET or PET/CT is not part of the CWU of recurrent cervical cancer and is usually performed only as a problem solver at the end of the CWU. We believe that this policy should be changed in such a way that ${ }^{18} \mathrm{~F}$-FDG PET or PET/CT would be performed routinely in cases of a suspected recurrence of cervical cancer. Only then will ${ }^{18} \mathrm{~F}-\mathrm{FDG}$ PET or PET/CT decrease the time lag between diagnosis and treatment of recurrent cervical cancer, potentially improving patient outcomes. Prospective studies are warranted to investigate if early detection of recurrence by ${ }^{18} \mathrm{~F}-\mathrm{FDG}$ PET or PET/CT can prolong the survival or will reveal only the tip of the iceberg. The high positive predictive value of ${ }^{18} \mathrm{~F}$-FDG PET in patients with a suspected recurrence 
of cervical cancer suggests that inclusion in prospective intervention trials might be based on a positive ${ }^{18} \mathrm{~F}-\mathrm{FDG}$ PET scan.

\section{CONCLUSION}

${ }^{18}$ F-FDG PET can help to clarify the diagnosis of clinically suspected recurrent cervical cancer. In this patient population, ${ }^{18} \mathrm{~F}$-FDG PET had significant value in diagnostic understanding and management of recurrent cervical cancer, facilitating decision making and treatment planning.

\section{APPENDIX}

\section{Questionnaire on Impact of ${ }^{18}$ F-FDG PET}

Part I: CWU questions based on patient's files, before ${ }^{18} \mathrm{~F}-\mathrm{FDG}$ PET had been performed (here radiologic reports were presented)

1. A. Do you think that the work-up before ${ }^{18}$ F-FDG PET was adequate?

Yes

$\square$ No

B. If no, which additional investigations would you have applied?

Laboratory investigations (specify)...

X-ray, because...

CT scan, because...

MRI scan, because...

Bone scintigraphy, because...

$\square$ Other (specify)...

2. A. On the basis of the results obtained before ${ }^{18} \mathrm{~F}-\mathrm{FDG}$ PET, what is the most likely diagnosis?

$\square$ No recurrence

$\square$ Recurrence:

$\square$ Local recurrence

Regional recurrence

$\square$ Distant metastases

B. How confident are you about this diagnosis?

0

50

100

(percentage)

3. A. On the basis of the data obtained before ${ }^{18} \mathrm{~F}-\mathrm{FDG}$ PET, which management do you propose?

$\square$ Surgery, namely...

Radiotherapy, namely...

$\square$ Chemoradiation, namely...

Hyperthermia

$\square$ Chemotherapy, namely...

$\square$ Palliative

$\square$ Expectative

B. What is the intent of this management?

$\square$ Curative

$\square$ Palliative

PART II: ${ }^{18}$ F-FDG PET results

Questions after ${ }^{18} \mathrm{~F}-\mathrm{FDG}$ PET had been performed (here

${ }^{18}$ F-FDG PET results of the masked nuclear medicine physician were presented)
4. Would you perform additional investigations?

$\square$ Yes,

$\square$ Laboratory investigations (specify)...

$\mathrm{X}$-ray, because...

CT scan, because...

MRI scan, because...

Bone scintigraphy, because...

Other, specify...

$\square$ No

5. A. On the basis of the results including ${ }^{18} \mathrm{~F}-\mathrm{FDG}$ PET, what is the most likely diagnosis?

$\square$ No recurrence

$\square$ Recurrence:

$\square$ Local recurrence

$\square$ Regional recurrence

$\square$ Distant metastases

B. How confident are you about this diagnosis?

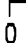

50

(percentage)

6. A. On the basis of the results of ${ }^{18}$ F-FDG PET, which management do you propose?

$\square$ Surgery, namely...

$\square$ Radiotherapy, namely...

$\square$ Chemoradiation, namely...

$\square$ Hyperthermia

$\square$ Chemotherapy, namely...

$\square$ Palliative

$\square$ Expectative

B. What is the intent of this management?

$\square$ Curative

$\square$ Palliative

PART III: Original treatment plan and follow-up

Question based on the final treatment and follow-up (here the original treatment and follow-up were provided)

7. After appropriate follow-up, what is the impact of ${ }^{18} \mathrm{~F}-$ FDG PET on this patient? (Adapted from Wittenberg et al. (15-17).)

$\square{ }^{18}$ F-FDG PET led me to choose therapy that, in retrospect, was not in the best interest of the patient. ${ }^{18}$ F-FDG PET led to investigations I would not otherwise have performed, but this did not harm the patient.

${ }^{18}$ F-FDG PET was of no influence in my diagnosis and choice of treatment.

$\square{ }^{18}$ F-FDG PET provided information that substantially improved my understanding of this patient's disease but did not alter my choice of treatment.

$\square{ }^{18}$ F-FDG PET led to a better diagnosis and led to a beneficial change in management.

\section{ACKNOWLEDGMENTS}

We thank Lotty Hooft for help with data analysis and interpretation. 


\section{REFERENCES}

1. Jemal A, Murray T, Samuels A, Ghafoor A, Ward E, Thun MJ. Cancer statistics, 2003. CA Cancer J Clin. 2003;53:5-26.

2. Friedlander M. Guidelines for the treatment of recurrent and metastatic cervical cancer. Oncologist. 2002;7:342-347.

3. Waggoner SE. Cervical cancer. Lancet. 2003;361:2217-2225.

4. Ijaz T, Eifel PJ, Burke T, Oswald MJ. Radiation therapy of pelvic recurrence after radical hysterectomy for cervical carcinoma. Gynecol Oncol. 1998;70: 241-246.

5. Kecmanovic DM, Pavlov MJ, Kovacevic PA, Sepetkovski AV, Ceranic MS, Stamenkovic AB. Management of advanced pelvic cancer by exenteration. Eur J Surg Oncol. 2003;29:743-746.

6. Vermorken JB, Zanetta G, De Oliveira CF, et al. Randomized phase III trial of bleomycin, vindesine, mitomycin- $\mathrm{C}$, and cisplatin (BEMP) versus cisplatin (P) in disseminated squamous-cell carcinoma of the uterine cervix: an EORTC Gynecological Cancer Cooperative Group study. Ann Oncol. 2001;12:967-974.

7. Choi JI, Kim SH, Seong CK, Sim JS, Lee HJ, Do KH. Recurrent uterine cervical carcinoma: spectrum of imaging findings. Korean J Radiol. 2000;1:198-207.

8. Weber TM, Sostman HD, Spritzer CE, et al. Cervical carcinoma: determination of recurrent tumor extent versus radiation changes with MR imaging. Radiology. 1995;194:135-139.

9. Havrilesky LJ, Wong TZ, Secord AA, Berchuck A, Clarke-Pearson DL, Jones EL. The role of PET scanning in the detection of recurrent cervical cancer. Gynecol Oncol. 2003;90:186-190.

10. Lai $\mathrm{CH}$, Huang $\mathrm{KG}$, See LC, et al. Restaging of recurrent cervical carcinoma with dual-phase $\left[{ }^{18} \mathrm{~F}\right]$ fluoro-2-deoxy-D-glucose positron emission tomography. Cancer: 2004;100:544-552.

11. Unger JB, Ivy JJ, Connor P, et al. Detection of recurrent cervical cancer by whole-body FDG PET scan in asymptomatic and symptomatic women. Gynecol Oncol. 2004;94:212-216.

12. Van der Veldt AA, Hooft L, Van Diest PJ, et al. Microvessel density and p53 in detecting cervical cancer by FDG PET in cases of suspected recurrence. Eur J Nucl Med Mol Imaging. 2006;33:1408-1416.
13. Chung HH, Jo H, Kang WJ, et al. Clinical impact of integrated PET/CT on the management of suspected cervical cancer recurrence. Gynecol Oncol. 2007;104: 529-534.

14. Joshi U, Raijmakers PG, Riphagen II, Teule GJ, Van Lingen A, Hoekstra OS. Attenuation-corrected vs. nonattenuation-corrected 2-deoxy-2-[F-18]fluoroD-glucose-positron emission tomography in oncology: a systematic review. Mol Imaging Biol. 2007;9:99-105.

15. Herder GJ, Van Tinteren H, Comans EF, et al. Prospective use of serial questionnaires to evaluate the therapeutic efficacy of ${ }^{18} \mathrm{~F}$-fluorodeoxyglucose (FDG) positron emission tomography (PET) in suspected lung cancer. Thorax. 2003;58:47-51.

16. Mijnhout GS, Comans EFI, Raijmakers P, et al. Reproducibility and clinical value of ${ }^{18} \mathrm{~F}$-fluorodeoxyglucose positron emission tomography in recurrent melanoma. Nucl Med Commun. 2002;23:475-481.

17. Wittenberg J, Fineberg HV, Ferrucci JT Jr, et al. Clinical efficacy of computed body tomography, II. AJR. 1980;134:1111-1120.

18. Fleiss JL. Reliability of measurement. In: Fleiss JL, ed. The Design and Analysis of Clinical Experiments. New York, NY: John Wiley Sons Inc.; 1986:17-31.

19. Belhocine T, Thille A, Fridman V, et al. Contribution of whole-body ${ }^{18} \mathrm{FDG}$ PET imaging in the management of cervical cancer. Gynecol Oncol. 2002;87: 90-97.

20. Husain A, Akhurst T, Larson S, Alektiar K, Barakat RR, Chi DS. A prospective study of the accuracy of ${ }^{18}$ fluorodeoxyglucose positron emission tomography ( ${ }^{18} \mathrm{FDG}$ PET) in identifying sites of metastasis prior to pelvic exenteration. Gynecol Oncol. 2007;106:177-180.

21. Yen TC, See LC, Chang TC, et al. Defining the priority of using ${ }^{18} \mathrm{~F}$-FDG PET for recurrent cervical cancer. J Nucl Med. 2004;45:1632-1639.

22. Bodurka-Bevers D, Morris M, Eifel PJ, et al. Posttherapy surveillance of women with cervical cancer: an outcomes analysis. Gynecol Oncol. 2000;78: 187-193.

23. Ryu SY, Kim MH, Choi SC, Choi CW, Lee KH. Detection of early recurrence with ${ }^{18}$ F-FDG PET in patients with cervical cancer. J Nucl Med. 2003;44:347-352.

24. Kitajima K, Murakami K, Yamasaki E, Domeki Y, Kaji Y, Sugimura K. Performance of FDG-PET/CT for diagnosis of recurrent uterine cervical cancer. Eur Radiol. 2008;18:2040-2047. 